\title{
ĐÁNH GIÁ THÍCH NGHI ĐẤT ĐAI HUYỆN CẦN GIÒ̀ THÀNH PHỐ HỒ CHÍ MINH
}

\author{
ĐINH ĐẠI GÁI \\ Viện Khoa học Công nghệ và Quản lý Môi truờng, Đại học Công nghiệp Thành phố Hồ Chí Minh; \\ dinhgaits@gmail.com
}

Tóm tắt. Để có cơ sở bố trí sản xuất theo hướng bền vững và phù hợp với điều kiện tự nhiên của một vùng lãnh thổ nhất định, thì đánh giá thích nghi đất đai là công việc đầu tiên và cần thiết. Nghiên cứu này được tiến hành theo hướng dẫn của TCVN 8409:2010 về đánh giá thích nghi đất đai. Trên cơ sở kết hợp chất lượng đất đai và yêu cầu sử dụng đất của các loại hình sử dụng đất để xác định mức độ thích hợp của các loại hình sử dụng đất với vùng đất đai cụ thể. Đề tài đã chọn được 5 loại hình sử dụng đất được lựa chọn để đánh giá: (1) Rau màu, (2) Cây ăn quả (Xoài, nhãn), (3) Nuôi trồng thủy sản, (4) Rừng ngập mặn và (5) Sản xuất muối. Căn cứ vào yêu cầu sử dụng đất của 5 loại hình này, kết hợp tính chất đất đai (14 đơn vị đất đai) để đánh giá khả năng thích nghi; Mỗi loại hình sử dụng đất có thể thích nghi với nhiều đơn vị đất đai và ngược lại mỗi đơn vị đất đai cũng có thể thích nghi với nhiều loại hình sử dụng đất khác nhau. Căn cứ vào kết quả nghiên cứu, tham khảo kịch bản biến đổi khí hậu của TP. HCM cũng như định hướng qui hoạch sử dụng đất, đề tài đề xuất 5 loại hình sử dụng đất có khả năng phát triển tại địa phương. Kết quả nghiên cứu cung cấp cơ sở khoa học để bố trí các loại hình sử dụng đất phù hợp và bền vững.

Keywords: Đánh giá thích nghi đất đai, loại hình sử dụng đất, kịch bản biến đổi khí hậu.

\section{LAND SUITABILITY EVALUATION IN CAN GIO DISTRST HO CHI MINH CITY}

\begin{abstract}
In order to have a basis for arranging production in a sustainable manner and in accordance with the natural conditions of a given territory, land suitability evaluation is the first and necessary task. This study was conducted under the guidance of TCVN 8409: 2010 on land suitability evaluation. Based on the matching of land quality and land use requirements of land use types. The topic has chosen 5 land use types were selected for evaluation: (1) Vegetables, (2) Fruit trees (Mango, longan), (3) Aquaculture, (4) Mangrove forest and (5) Salt production. Based on the land use requirements of these 5 types, a matching of land properties (14 land units) is used to assess suitability; Each type of land use can be adapted to many land units and vice versa each land unit can also be adapted to many different types of land use. Based on the research results, refer to the climate change scenario of the HCM City as well as the orientation of land use planning, the author proposes 5 types of land use that can be developed in Cần Giờ distrist. The research results provide a scientific basis for arranging suitable and sustainable land use types.
\end{abstract}

Keywords: land suitability evaluation, land use types, climate change scenario.

\section{I. ĐẠT V VẤN Đî̀}

Tiếp cận với biển Đông, huyện Cần Giờ có vai trò rất quan trọng đối với Tp HCM, Huyện có khu rừng ngập mặn đan xen với hệ thống sông rạch dày đặc, chứa đựng các hệ sinh thái mang tính đa dạng sinh học cao với nhiều loài động thực vật đặc hữu của miền Duyên hải Việt Nam, đó là khu rừng ngập mặn (RNM) Cần Giờ. Rừng ngập mặn là một trong những kiểu rừng có khả năng hấp thụ khí $\mathrm{CO}_{2}$ và tích lũy carbon trong sinh khối cao nhất tại vùng nhiệt đới - chứa bình quân $1.029 \mathrm{Mg}$ carbon trên mỗi hecta [1]. RNM Cần Giờ đóng vai trò quan trọng trong việc điều hòa khí hậu cho thành phố và các tỉnh lân cận, vừa bảo vệ vùng ven bờ, chống sạt lở, hạn chế sự xâm nhập mặn vào đất liền, bảo tồn hệ sinh thái đất ngập nước. Vì vậy Huyện Cần Giờ được định hướng phát triển là đô thị xanh du lịch sinh thái nghỉ dưỡng của thành phố HCM và khu vực [2]. Do đó việc sử dụng đất của huyện cũng sẽ biến động theo các hoạt động phát triển kinh tế hiện tại và trong tương lai, gây sức ép đối với đất đai. Sử dụng đất đai như thế nào cho hợp lý và có hiệu quả là vấn đề luôn được quan tâm; đặc biệt trong hoàn cảnh dân số ngày càng tăng, nhu cầu về lương thực thực phẩm chưa đáp ứng, đất canh tác đang bị thoái hoá và thu hẹp, môi trường sống đang bị ô nhiễm trầm trọng. Đánh giá thích nghi đất đai (ĐGTNĐĐ) là yêu cầu không thể thiếu được trong quy hoạch sử dụng đẩt [3]. Xu thế kết hợp giữa kết quả nghiên cứu đất và đánh giá đất đai trên thế giới hiện nay được thể hiện trong các đề cương công tác và chương trình hội thảo của nhiều tổ chức quốc tế [4]. Trong gần ba thập 
niên trở lại đây, tổ chức Lương-Nông Quốc tế (FAO) đã có những hoạt động về nghiên cứu đất, những hoạt động này tập trung vào: (1) lập bản đồ tài nguyên đất, (2) đánh giá đất đai, (3) nghiên cứu hiệu suất tiềm năng của đất và (4) sử dụng quản lý và bảo vệ đất [4]. Đặc điểm đất đai huyện Cần Giờ đã được xác định từ dự án trước đây [5]. Theo tài liệu này [5] đất đai huyện Cần Giờ được chia thành 7 nhóm; Từ năm 2004 đến nay (2020) có nhiều thay đổi (dân cư tăng, khai thác rừng nuôi tôm, sản xuất nông nghiệp...) làm cho môi trường đất cũng do vậy mà thay đổi theo chiều hướng bất lợi (Phèn hóa, mặn hóa). Vì vậy để nắm rõ đặc điểm tính chất đất đai, cần thiết phải đánh giá lại tính chất đất đai để ĐGTNĐĐ, trên cơ sở này bố trí sản xuất theo hướng bền vững và phù hợp với định hướng của $\mathrm{TP}$. Hồ Chí Minh nói riêng và của Vùng Kinh tế trọng điểm phía Nam.

\section{VÂT LIÊU VÀ PHƯƠNG PHÁP}

1/ Điều tra, bổ sung xây dựng bản đồ đất: áp dụng theo "Quy trình điều tra lập bản đồ đất tỷ lệ lớn" TCVN 9487-2012 [3]; Số tuyến khảo sát bổ sung: tiến hành khảo sát bổ sung 04 tuyến; Tổng số phẫu diện quan trắc bổ sung: 20 phẫu diện, trong đó: Phẫu diện chính phân tích: 3 phẫu diện; Phẫu diện phụ: 9 phẫu diện; Phẫu diện thăm dò: 8 phẫu diện; Căn cứ vào sự thay đồi hiện trạng sử dụng đất để tiến hành lấy mẫu.

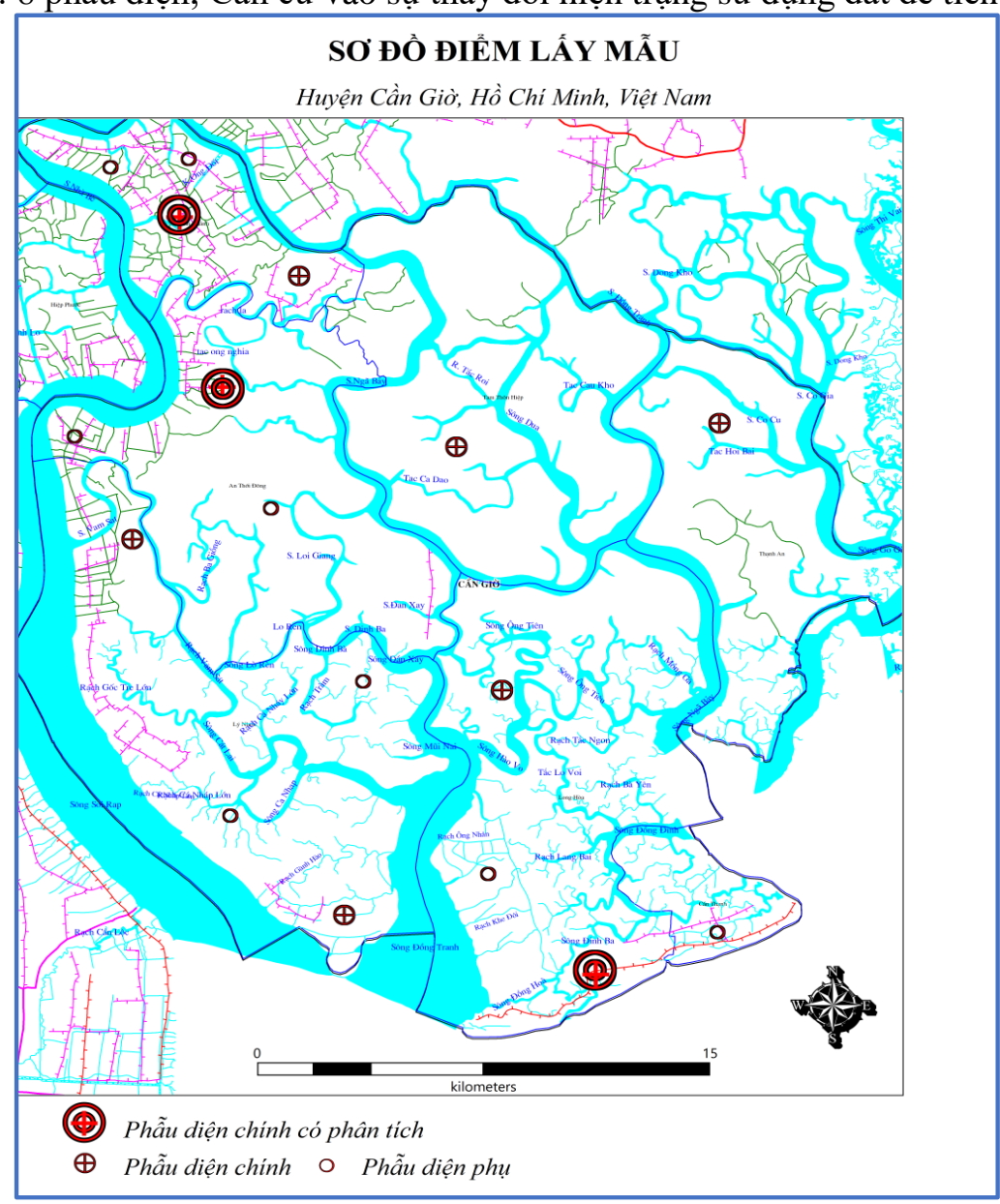

Hình 1. Sơ đồ vị trí lấy mẫu

2/ Chỉ tiêu và phương pháp phân tích: Theo hướng dần TCVN 9487-2012 [3]. Chỉ tiêu vật lí: Tỷ trọng, dung trọng, độ xốp, thành phần cơ giới; Chỉ tiêu hóa học: chỉ tiêu tổng số gồm $\mathrm{OC}, \mathrm{N}, \mathrm{P}_{2} \mathrm{O}_{5}, \mathrm{~K}_{2} \mathrm{O}$; chỉ tiêu dễ tiêu gồm $\mathrm{P}_{2} \mathrm{O}_{5}, \mathrm{~K}_{2} \mathrm{O}$; Độ chua trao đổi, thủy phân, $\mathrm{EC}$; Cation trao đổi: $\mathrm{Ca}^{2+}, \mathrm{Mg}^{2+}, \mathrm{Na}^{+}, \mathrm{K}^{+} ; \mathrm{CEC}, \mathrm{BS}$, $\mathrm{Cl}^{-}, \mathrm{SO}_{4}{ }^{2-}$.

3/ Đánh giá thích nghi đất đai: theo hướng dẫn TCVN 8409-2010 [3]. 


\section{KẾT QUẢ NGHIÊN CÚU VÀ THẢO LUẬN}

\subsection{Xây dụng bản đồ đất bổ sung}

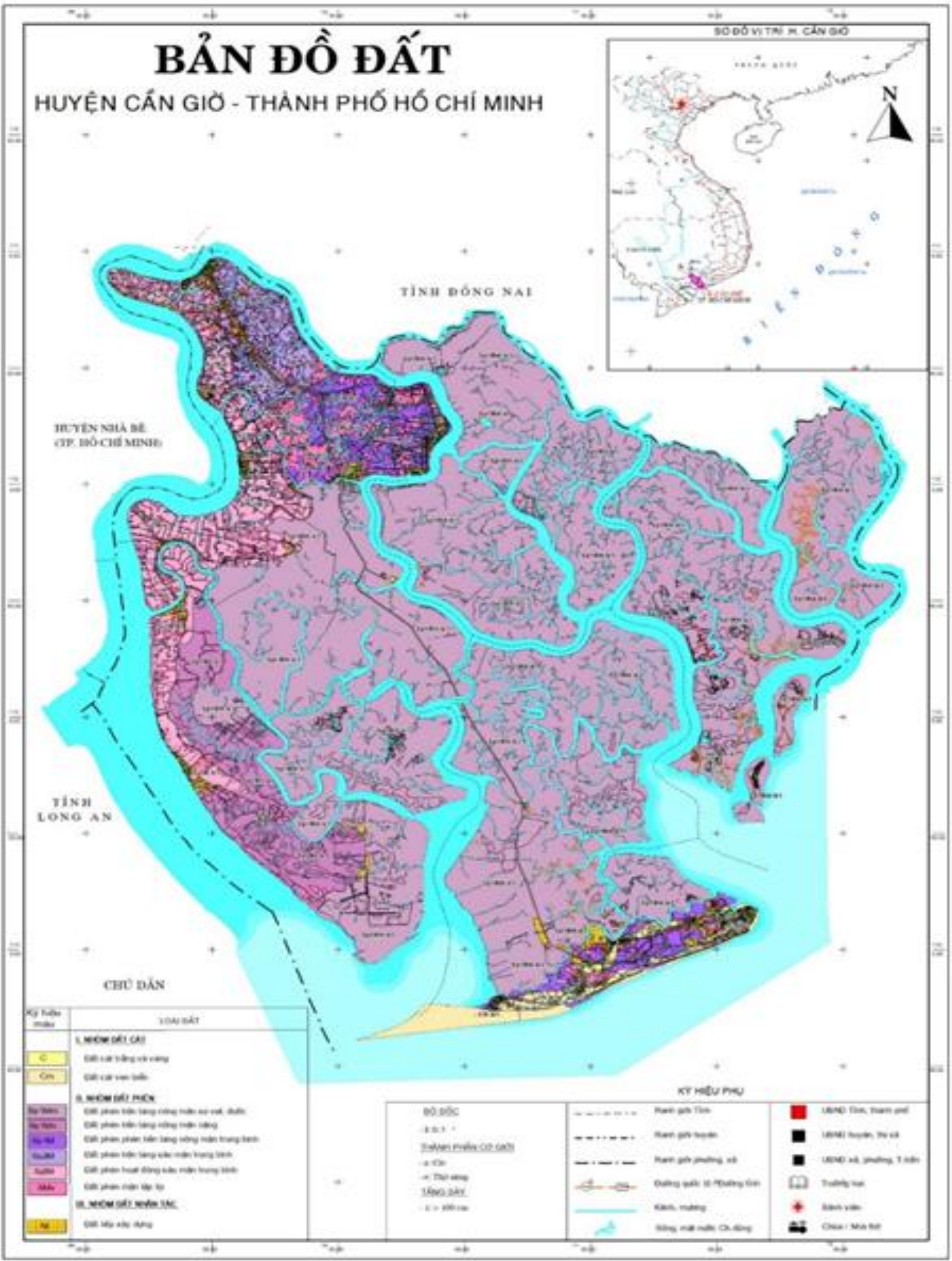

Hình 2 Bản đồ đất huyện Cần Giờ TP. Hồ Chí Minh 


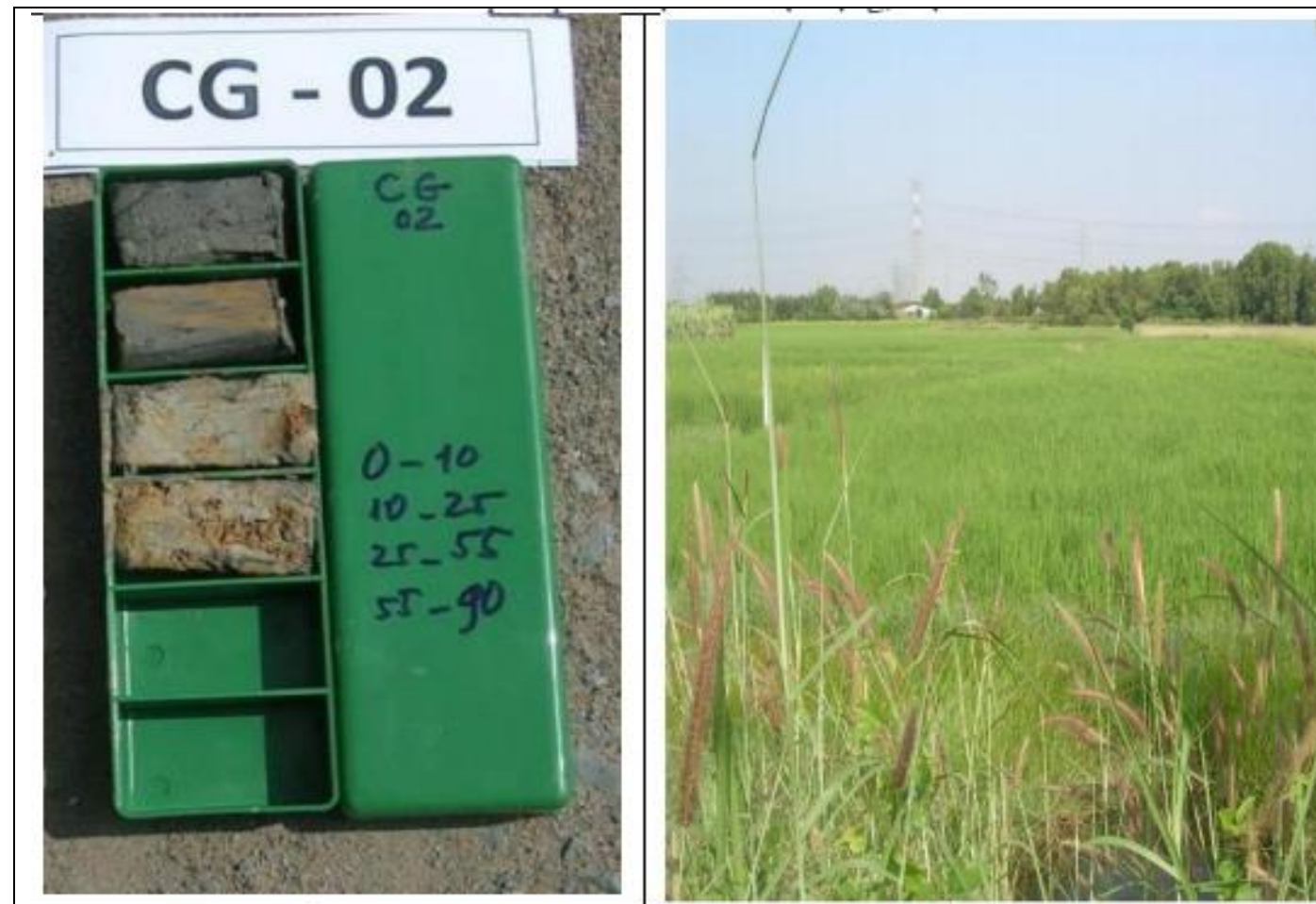

Phẩu diện đất phèn hoạt động, mặn (Xã An Thới Đông, Cần Giờ - TP. HCM) (Tọ độ X: 10.583288, Y: 106.802166)

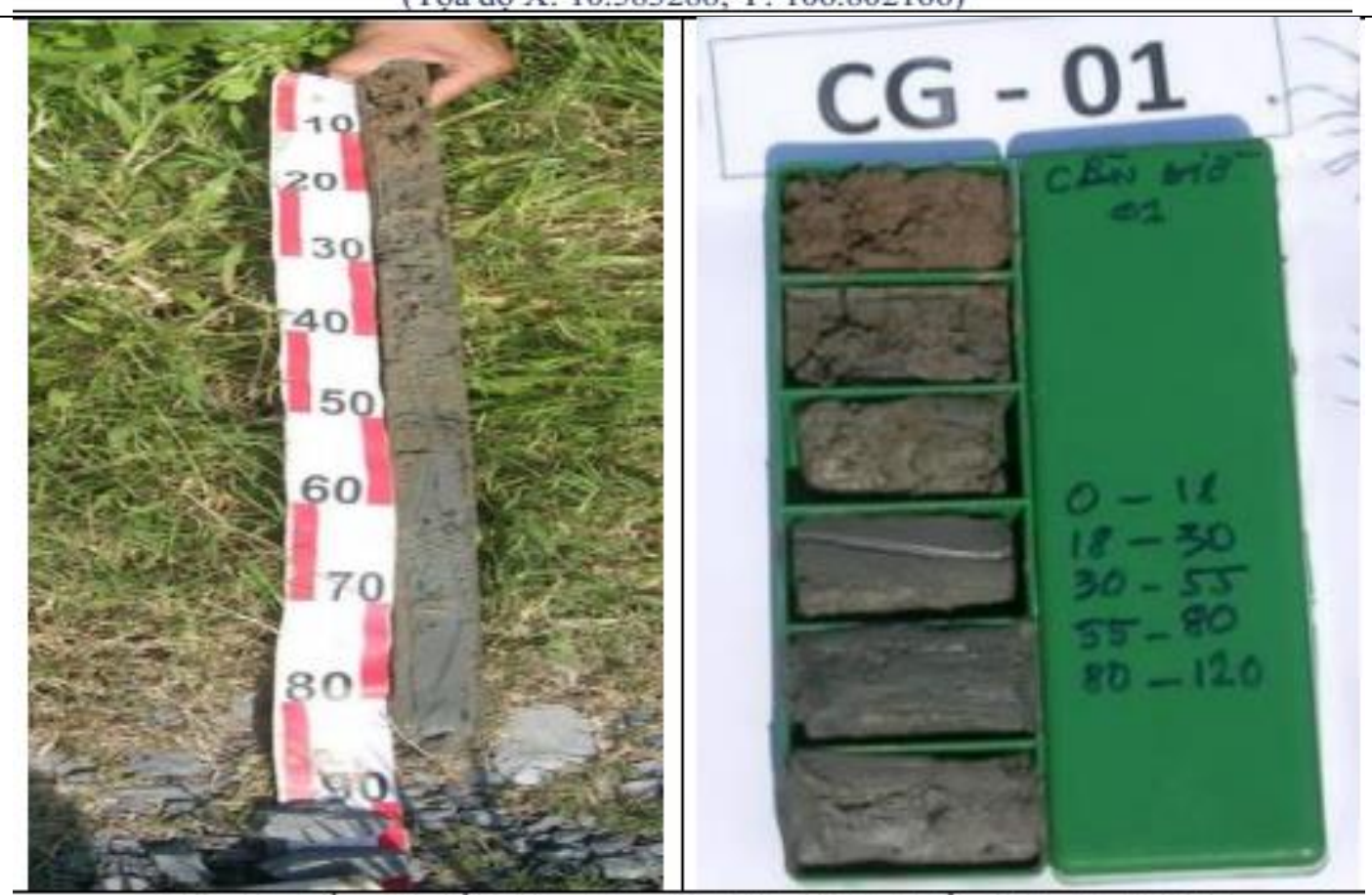

Phẫu diện đất phèn tiềm tàng, mặn (Xã Bình Khánh, Cần Giờ - TP. HCM)

(Tọa độ X: 10.626988, Y: 106.786030)

Hình 3. Một số hình ảnh thực địa

Kết quả điều tra bổ sung xác định đất huyện Cần Giờ được phân loại thành 3 Nhóm (Group) với 9 Đơn vị bản đồ (Soil Unit); các tác giả trước đây [6], [7], [8] đã phân loại thành 6 Nhóm và Đơn vị đất chưa phân chi tiết (Do tỉ lệ bản đồ). Ba nhóm đất được xác định: (1) Nhóm đất cát, (2) Nhóm đất phèn và (3) Nhóm đất nhân tác (Bảng 1$)$. Nhóm đất cát được phân thành 2 đơn vị đất, (1) Đất cát trắng và vàng và (2) Đất cát ven biển. Diện tích 1.223,29 ha, chiếm 1,74\% DTTN; Nhóm đất phèn, diện tích 48.311,56 ha, chiếm 
68,58\% DTTN, Chia thành 4 đơn vị đất: Đất phèn hoạt động, có 2 đơn vị, bao gồm (1) Đất phèn hoạt động sâu mặn trung bình, (2) Đất phèn mặn lập líp. Đất phèn tiềm tàng, có 4 đơn vị, bao gồm (1) Đất phèn tiềm tàng nông mặn sú vẹt, đước; (2) Đất phèn tiềm tàng nông mặn nặng; (3) Đất phèn tiềm tàng nông mặn trung bình; (4) Đất phèn TT sâu mặn trung bình. Nhóm đất nhân tác, có 1 đơn vị là Đất lập líp, diện tích 884,81 ha, chiếm $1,26 \%$ DTTN.

Bảng 1. Thống kê diện tích đất huyện Cần Giờ

\begin{tabular}{|c|c|c|c|c|c|}
\hline \multirow[b]{2}{*}{ Nhóm đất } & \multicolumn{2}{|c|}{ Đơn vị bản đồ } & \multirow{2}{*}{ Ký hiệu } & \multirow{2}{*}{$\begin{array}{l}\text { Diện tích } \\
\text { (ha) }\end{array}$} & \multirow{2}{*}{$\begin{array}{l}\text { Tỷ lệ } \\
(\%)\end{array}$} \\
\hline & Việt Nam & $\begin{array}{l}\text { Tương đương FAO- } \\
\text { UNESCO }\end{array}$ & & & \\
\hline \multirow[t]{3}{*}{ I. Đất cát } & & & & 1223.29 & 1.73 \\
\hline & 1. Đất cát trắng và vàng & (Luvic Arenosols) & $\mathrm{C}$ & 272.10 & 0.39 \\
\hline & 2. Đất cát ven biển & (Haplic Arenosols) & $\mathrm{Cm}$ & 951.19 & 1.35 \\
\hline \multirow[t]{7}{*}{ II.Đất phèn } & & & & 48311.56 & 68.58 \\
\hline & $\begin{array}{l}\text { 3. Đất phèn tiềm tàng nông } \\
\text { mặn sú vẹt, đước }\end{array}$ & $\begin{array}{l}\text { (Sali-Proto-Thhionic } \\
\text { Fluvisols). }\end{array}$ & Sp1Mm & 36269.06 & 51.49 \\
\hline & $\begin{array}{l}\text { 4. Đất phèn tiềm tàng nông } \\
\text { mặn nặng }\end{array}$ & $\begin{array}{l}\text { (Sali-Proto-Thhionic } \\
\text { Fluvisols) }\end{array}$ & Sp1Mn & 2873.20 & 4.08 \\
\hline & $\begin{array}{l}\text { 5. Đất phèn tiềm tàng nông } \\
\text { mặn trung bình }\end{array}$ & $\begin{array}{l}\text { (Sali-Proto-Thhionic } \\
\text { Fluvisols) }\end{array}$ & Sp1M & 1542.34 & 2.19 \\
\hline & $\begin{array}{l}\text { 6. Đất phèn TT sâu mặn } \\
\text { trung bình }\end{array}$ & $\begin{array}{l}\text { (Sali-Proto-Thhionic } \\
\text { Fluvisols ) }\end{array}$ & $\mathrm{Sp} 2 \mathrm{M}$ & 1043.30 & 1.48 \\
\hline & $\begin{array}{l}\text { 7. Đất phèn hoạt động sâu } \\
\text { mặn trung bình }\end{array}$ & $\begin{array}{l}\text { (Sali-Orthi-Thhionic } \\
\text { Fluvisols) }\end{array}$ & Sj2M & 3458.73 & 4.91 \\
\hline & 8. Đất phèn mặn lập líp & & $\mathrm{SMv}$ & 3124.94 & 4.44 \\
\hline $\begin{array}{l}\text { III. Đất nhân } \\
\text { tác }\end{array}$ & 9. Đất líp xây dựng & & $\mathrm{Nt}$ & 884.81 & 1.26 \\
\hline \multicolumn{4}{|l|}{ Sông suối } & 20025.68 & 28.43 \\
\hline \multicolumn{4}{|l|}{ DTTN } & 70445.34 & 100.00 \\
\hline
\end{tabular}

\section{2 Đánh giá thích nghi đất đai}

\subsubsection{Xây dựng bản đồ Đơn vị đất đai}

Căn cứ vào các kết quả điều tra nghiên cứu đất và những kết quả điều tra thực tế về tình hình sử dụng đất của huyện, các yếu tố được đưa ra xem xét để xây dựng bản đồ đơn vị đất đai, làm cơ sở cho việc đánh giá khả năng thích nghi đất đai, bao gồm: (I) Đặc trưng về đất: (1) Nhóm đất, (2) Thành phần cơ giới, (3) Độ sâu xuất hiện glây, (4) Độ sâu xuất hiện tầng phèn (phèn hoạt động hoặc tiềm tàng, (5) Độ mặn. (II) Đặc trưng về địa hình: (6) Dạng địa hình địa mạo.

Bảng 2. Các chỉ tiêu xây dựng bản đồ đơn vị đất đai huyện Cần Giờ

\begin{tabular}{|l|c|c|c|}
\multicolumn{1}{|c|}{ Chỉ tiêu } & Tiêu chuẩn & Mã số & Ký hiệu \\
\hline I. Đặc trưng về đất & & & \\
\hline 1. Nhóm đất & & & $\boldsymbol{d}$ \\
\hline - Đất Cát & $\mathrm{C}$ & 1 & $\mathrm{~d} 1$ \\
\hline - Đất phèn hoạt động mặn & $\mathrm{Sj}$ & 2 & $\mathrm{~d} 2$ \\
\hline - Đất phèn tiềm tàng mặn & $\mathrm{Sp}$ & 3 & $\mathrm{~d} 3$ \\
\hline - Đất phèn mặn ít & $\mathrm{SMv}$ & 4 & $\mathrm{~d} 4$ \\
\hline - Đất nhân tác & $\mathrm{Nt}$ & 5 & $\mathrm{~d} 5$ \\
\hline 2. Thành phần co giới & & & $\boldsymbol{c}$ \\
\hline - Thành phần cơ giới nhẹ & Cát, Thịt nhẹ & 1 & $\mathrm{c} 1$ \\
\hline - Thành phần cơ giới nặng & Thịt nặng- sét & 2 & $\mathrm{c} 2$ \\
\hline
\end{tabular}




\begin{tabular}{|c|c|c|c|}
\hline Chỉ tiêu & Tiêu chuẩn & Mã số & Ký hiệu \\
\hline 3. Độ sâu xuất hiện glây & & & $g$ \\
\hline - Không có glây trong vòng $0-125 \mathrm{~cm}$ & 0 & 1 & $\mathrm{~g} 1$ \\
\hline - Glây "treo" (xuất hiện trong vòng 0-50cm) & $<50 \mathrm{~cm}$ & 2 & $\mathrm{~g} 2$ \\
\hline - Glây toàn phẫu diện & $50-125 \mathrm{~cm}$ & 3 & g3 \\
\hline 4. Độ sâu xuất hiện tầng phèn hoạt động & & & $j$ \\
\hline - Không có phèn h.động trong vòng $0-125 \mathrm{~cm}$ & 0 & 1 & $\mathrm{j} 1$ \\
\hline - Tầng phèn h.động nông & $0-50 \mathrm{~cm}$ & 2 & $\mathrm{j} 2$ \\
\hline - Tầng phèn hoạt động trung bình & $>50-80 \mathrm{~cm}$ & 3 & $\mathrm{~J} 3$ \\
\hline - Tầng phèn hoạt động sâu & $>80 \mathrm{~cm}$ & 4 & $\mathrm{~J} 4$ \\
\hline 5. Độ sâu xuất hiện tầng phèn tiềm tàng & & & $p$ \\
\hline - Không có phèn TT trong vòng $0-125 \mathrm{~cm}$ & 0 & 1 & $\mathrm{p} 1$ \\
\hline - Thèn t.tàng nông & $0-50 \mathrm{~cm}$ & 2 & $\mathrm{p} 2$ \\
\hline - Tầng phèn tiềm tàng trung bình & $>50-80 \mathrm{~cm}$ & 3 & $\mathrm{p} 3$ \\
\hline - Tầng phèn tiềm tàng rất sâu & $>80 \mathrm{~cm}$ & 4 & $\mathrm{p} 4$ \\
\hline \multicolumn{4}{|l|}{ II. Đặc trưng về địa hình } \\
\hline 6. Dạng địa hình địa mạo & & & $\boldsymbol{h}$ \\
\hline - Dạng không ngập & có cao trình từ 2 đến $10 \mathrm{~m}$ Cao, & 1 & h1 \\
\hline - Dạng ngập theo chu kỳ nhiều năm & 1,5 đến $2,0 \mathrm{~m}$ & 2 & $\mathrm{~h} 2$ \\
\hline - Dạng ngập theo chu kỳ năm & từ 1,0 đến $1,5 \mathrm{~m}$, & 3 & $\mathrm{~h} 3$ \\
\hline - Dạng ngập theo chu kỳ tháng & từ 0,5 đến $1,0 \mathrm{~m}$ & 4 & $\mathrm{~h} 4$ \\
\hline - Dạng ngập theo chu kỳ ngày & từ 0 đến $0,5 \mathrm{~m}$ & 5 & h5 \\
\hline - Dạng bãi bồi ven biển và cửa sông & cao $<0,5 \mathrm{~m}$ & 6 & h6 \\
\hline
\end{tabular}

Trên cơ sở chồng xếp 6 loại bản đồ đơn tính của 6 yếu tố đất đai nêu trên (bảng 2), đã xác định được 14 đơn vị đất đai (Land Mapping Unit= LMU). Mỗi ĐVĐĐ thể hiện tính chất đồng nhất của 6 yếu tố đơn tính; ví dụ: ĐVĐĐ số 1 có loại đất là đất cát $(\mathrm{C})$, thành phần cơ giới là cát $(\mathrm{a})$, tính chất gley không xuất hiện $(\mathrm{N})$, không có sự xuất hiện tầng phèn $(\mathrm{N})$, độ cao tương đối $1,5-2 \mathrm{~m}$ và mức độ nhiễm mặn (Mặn nhiều).

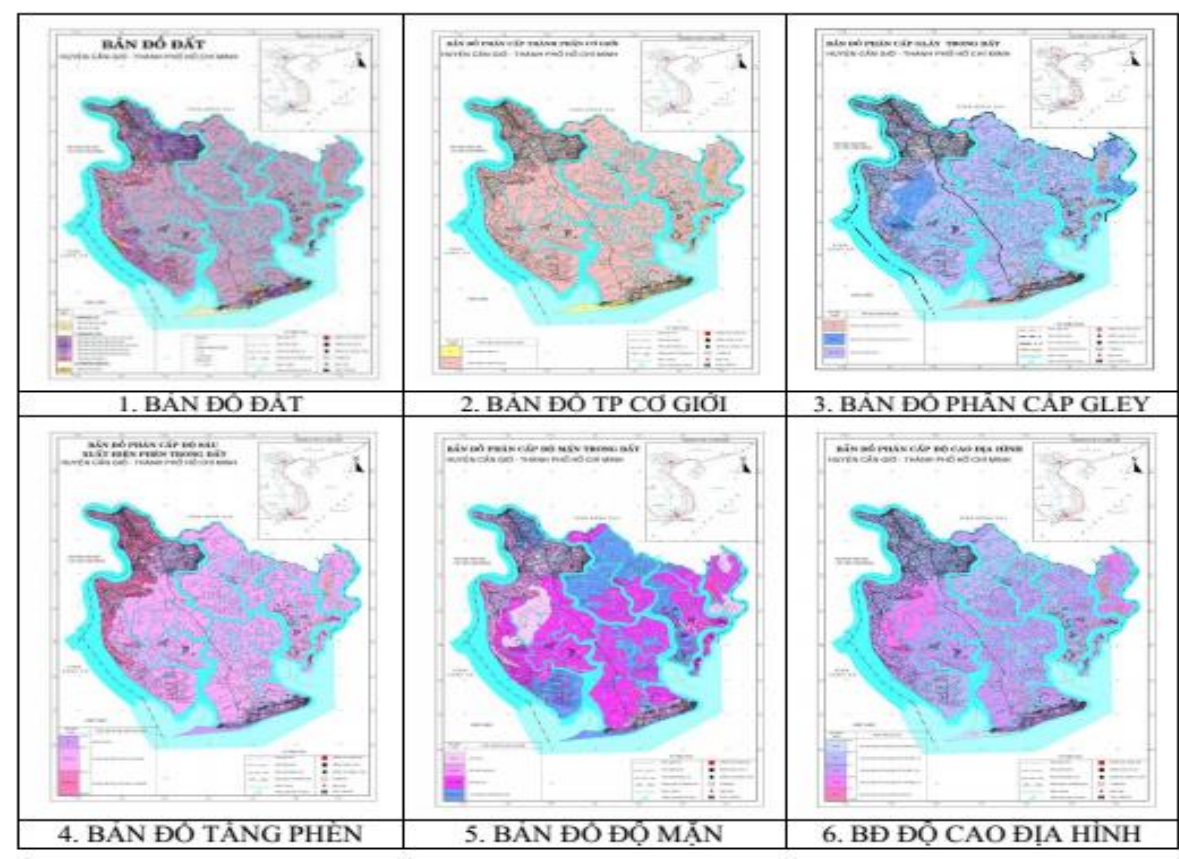

Hình 4. Các loại bản đồ đơn tính để xây dựng bản đồ đơn vị đất đai 


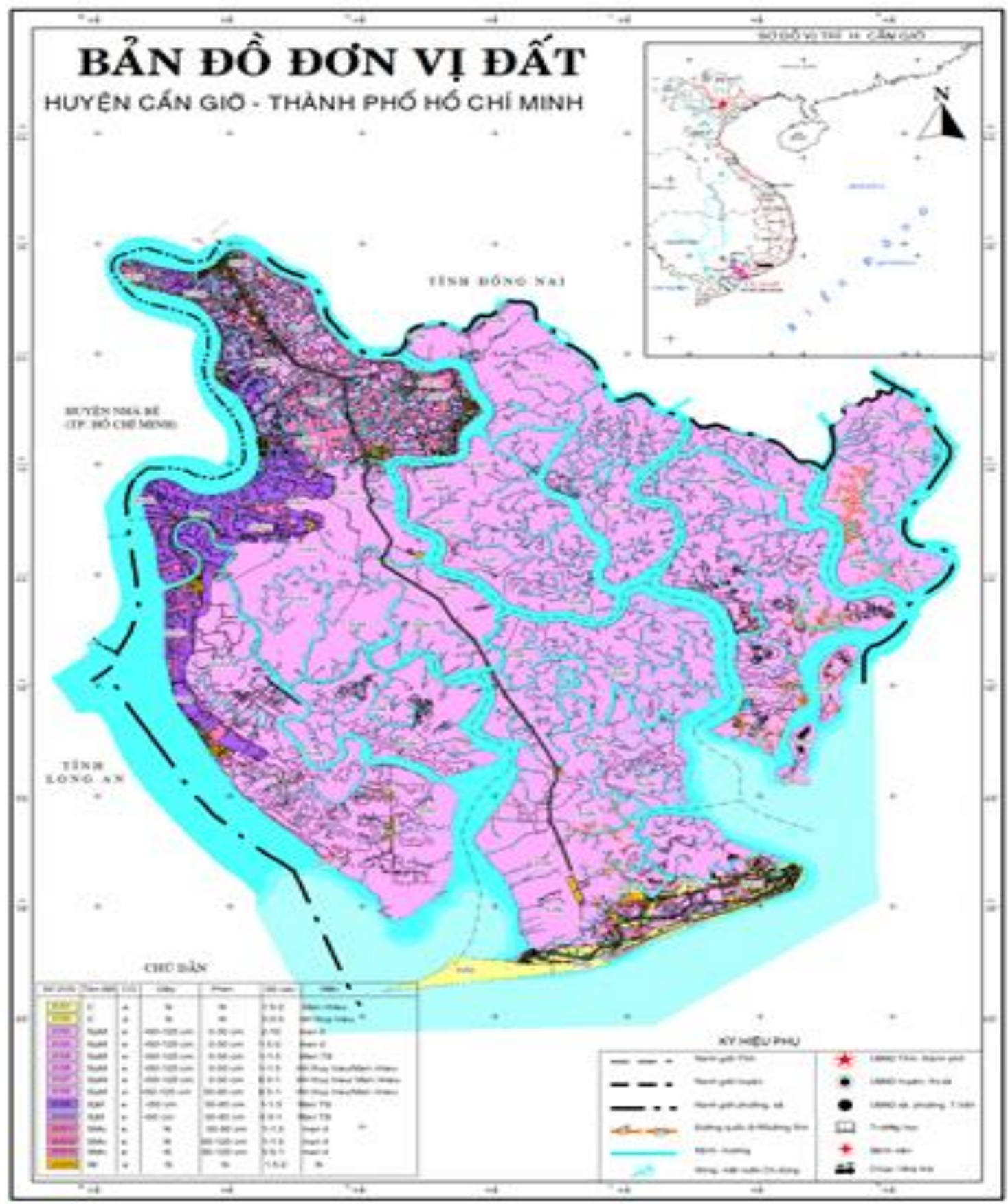

Hình 5. Bản đồ đơn vị đất đai 


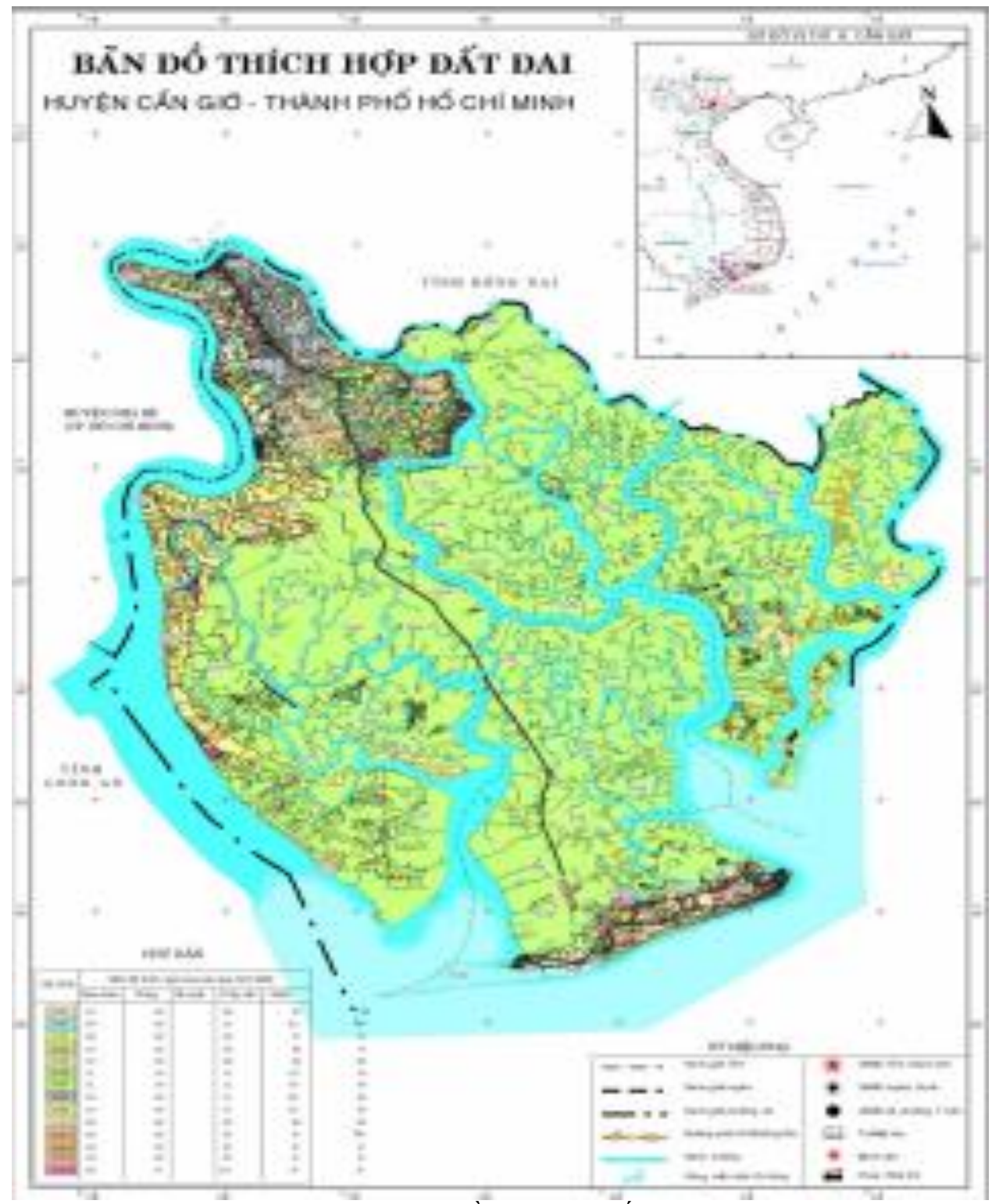

Hình 6. Bản đồ thich nghi đất đai

Bảng 3. Mô tả các đơn vị đất đai

\begin{tabular}{|c|c|c|c|c|c|c|c|}
\hline Số ĐVĐĐ & Tên đất & Cơ giới & Gley & Phèn & Độ cao & Mặn & Tổng \\
\hline DVD1 & $\mathrm{C}$ & \begin{tabular}{|l|}
$\mathrm{a}$ \\
\end{tabular} & $\mathrm{N}$ & $\mathrm{N}$ & $1.5-2 \mathrm{~m}$ & Mặn nhiều & 618.06 \\
\hline DVD2 & $\mathrm{C}$ & a & $\mathrm{N}$ & $\mathrm{N}$ & $0-0.5 \mathrm{~m}$ & Ảnh hưởng thủy triều & 605.23 \\
\hline DVD3 & SpM & $\mathrm{e}$ & $<50-125 \mathrm{~cm}$ & $0-50 \mathrm{~cm}$ & $2-10 m$ & Mặn ít & 77.22 \\
\hline DVD4 & SpM & $\mathrm{e}$ & $<50-125 \mathrm{~cm}$ & $0-50 \mathrm{~cm}$ & $1.5-2 \mathrm{~m}$ & Mặn ít & 4120.28 \\
\hline DVD5 & SpM & $\mathrm{e}$ & $<50-125 \mathrm{~cm}$ & $0-50 \mathrm{~cm}$ & $1-1.5 \mathrm{~m}$ & Mặn trung bình & 902.88 \\
\hline DVD6 & SpM & $\mathrm{e}$ & $<50-125 \mathrm{~cm}$ & $0-50 \mathrm{~cm}$ & $1-1.5 \mathrm{~m}$ & Ảnh hưởng thủy triều/Mặn nhiều & 22796.46 \\
\hline DVD7 & SpM & $\mathrm{e}$ & $<50-125 \mathrm{~cm}$ & $0-50 \mathrm{~cm}$ & $0.5-1 \mathrm{~m}$ & Ảnh hưởng thủy triều/Mặn nhiều & 12813.88 \\
\hline DVD8 & SpM & $\mathrm{e}$ & $<50-125 \mathrm{~cm}$ & $50-80 \mathrm{~cm}$ & $0.5-1 \mathrm{~m}$ & Ảnh hưởng thủy triều/Mặn nhiều & 1017.17 \\
\hline DVD9 & $\mathrm{SjM}$ & $\mathrm{e}$ & $<50 \mathrm{~cm}$ & $50-80 \mathrm{~cm}$ & $1-1.5 \mathrm{~m}$ & Mặn trung bình & 2818.46 \\
\hline DVD10 & SjM & $\mathrm{e}$ & $<50 \mathrm{~cm}$ & $50-80 \mathrm{~cm}$ & $0.5-1 \mathrm{~m}$ & Mặn trung bình & 640.27 \\
\hline DVD11 & SMv & $\mathrm{e}$ & $\mathrm{N}$ & $50-80 \mathrm{~cm}$ & $1-1.5 \mathrm{~m}$ & Mặn ít & 1411.27 \\
\hline DVD12 & SMv & $\mathrm{e}$ & $\mathrm{N}$ & $80-125 \mathrm{~cm}$ & $1-1.5 \mathrm{~m}$ & Mặn ít & 969.12 \\
\hline DVD13 & SMv & $\mathrm{e}$ & $\mathrm{N}$ & $80-125 \mathrm{~cm}$ & $0.5-1 \mathrm{~m}$ & Mặn ít & 744.55 \\
\hline DVD14 & $\mathrm{Nt}$ & $\mathrm{e}$ & $\mathrm{N}$ & $\mathrm{N}$ & $1.5-2 \mathrm{~m}$ & $\mathrm{~N}$ & 884.81 \\
\hline Sông suối & \multicolumn{6}{|c|}{ Không đánh giá } & 20025.68 \\
\hline Tổng DTTN & & & & & & & 70445.34 \\
\hline
\end{tabular}




\subsubsection{Xác định yêu cầu sủ dụng đất các loại hình SDĐ được chọn lựa}

Yêu cầu sử dụng đất là những đòi hỏi về điều kiện tự nhiên của các loại hình sử dụng đất. Việc xác định yêu cầu sử dụng đất là một nội dung rất quan trọng trong đánh giá đất đai. Bởi vì, muổn biết một loại hình sử dụng đất nào đó có thể bố trí được trên một vùng đất cụ thể hay không trước hết phải căn cứ vào đặc điểm của vùng đất, đồng thời phải nắm rõ yêu cầu đất đai của cây trồng được bố trí. Qua điều tra thực tế, huyện Cần Giờ có 13 hệ thống sử dụng đất với 10 loại hình sử dụng đất khác nhau; căn cứ vào hiệu quả kinh tế, định hướng sử dụng đất và điều kiện tự nhiên, đã chọn ra 5 loại hình sử dụng đất: (1) Rau - màu, (2) rừng phòng hộ (rừng ngập mặn), (3) cây ăn quả (Xoài, nhãn), (4) nuôi trồng thủy sản nước mặn và (5) Sản xuất muối.

Bảng 4. Yêu cầu sử dụng đất của các LUT được chọn huyện Cần Giờ

\begin{tabular}{|c|c|c|c|c|c|c|}
\hline \multirow{2}{*}{ Loại hình sử dụng đất } & \multirow{2}{*}{ Yếu tố chuẩn đoán } & \multirow{2}{*}{$\begin{array}{c}\text { Kí } \\
\text { hiệu }\end{array}$} & \multicolumn{4}{|c|}{ Phân cấp thích nghi } \\
\hline & & & S1 & S2 & S3 & $\mathbf{N}$ \\
\hline LUT 1 & - Nhóm đất & $\mathrm{d}$ & 1 & - & 2,3 & - \\
\hline \multirow[t]{5}{*}{ Chuyên rau, màu } & - Thành phần cơ giới & $\mathrm{c}$ & 1 & 2 & - & - \\
\hline & - Độ sâu xuất hiện glây & $\mathrm{g}$ & 1,2 & 3 & - & - \\
\hline & - Độ sâu xuất hiện tầng jarosite & $\mathrm{j}$ & 1 & - & - & 2 \\
\hline & - Độ sâu xuất hiện tầng pyrite & $\mathrm{p}$ & 1 & 3 & - & 2 \\
\hline & - Địa hình tương đối & $\mathrm{h}$ & 1,3 & 2 & 4 & - \\
\hline LUT 2 & - Nhóm đất & $\mathrm{d}$ & 2,3 & 1 & - & - \\
\hline \multirow[t]{5}{*}{ Rừng phòng hộ } & - Thành phần cơ giới & $\mathrm{c}$ & 1 & 2 & - & - \\
\hline & - Độ sâu xuất hiện glây & $\mathrm{g}$ & $1,2,3$ & - & - & - \\
\hline & - Độ sâu xuất hiện tầng jarosite & $\mathrm{j}$ & 1 & 2 & - & - \\
\hline & - Độ sâu xuất hiện tầng pyrite & $\mathrm{p}$ & $1,2,3$ & - & - & - \\
\hline & - Địa hình tương đối & $\mathrm{h}$ & $3,4,5,6$ & 2 & 1 & - \\
\hline LUT 3 & - Nhóm đất & $\mathrm{d}$ & 1 & - & 2,3 & - \\
\hline Cây ăn quả & - Thành phần cơ giới & $\mathrm{c}$ & 1 & 2 & - & - \\
\hline \multirow{4}{*}{ (Xoài, nhãn) } & - Độ sâu xuất hiện glây & $\mathrm{g}$ & 1 & 2 & 3 & - \\
\hline & - Độ sâu xuất hiện tầng jarosite & $\mathrm{j}$ & 1 & - & - & 2 \\
\hline & - Độ sâu xuất hiện tầng pyrite & $\mathrm{p}$ & 1 & - & 2,3 & - \\
\hline & - Địa hình tương đối & $\mathrm{h}$ & 1 & 2,3 & - & $4,5,6$ \\
\hline LUT 4 & - Nhóm đất & $\mathrm{d}$ & 3 & - & 2 & 2 \\
\hline \multirow{5}{*}{ Thủy sản nước mặn } & - Thành phần cơ giới & $\mathrm{c}$ & 1 & 2 & - & - \\
\hline & - Độ sâu xuất hiện glây & $\mathrm{g}$ & 2,3 & - & - & 1 \\
\hline & - Độ sâu xuất hiện tầng jarosite & $\mathrm{j}$ & 1 & - & 2 & - \\
\hline & - Độ sâu xuất hiện tầng pyrite & $\mathrm{p}$ & $1,2,3$ & - & - & - \\
\hline & - Địa hình tương đối & $\mathrm{h}$ & $4,5,6$ & - & 2,3 & 1 \\
\hline LUT 5 & - Nhóm đất & $\mathrm{d}$ & 1,2 & - & - & - \\
\hline \multirow[t]{5}{*}{ Ruộng muối } & - Thành phần cơ giới & $\mathrm{c}$ & 1,2 & - & - & - \\
\hline & - Độ sâu xuất hiện glây & $\mathrm{g}$ & 1 & 2,3 & - & - \\
\hline & - Độ sâu xuất hiện tầng jarosite & $\mathrm{j}$ & - & - & $1,2,3$ & - \\
\hline & - Độ sâu xuất hiện tầng pyrite & $\mathrm{p}$ & - & - & $1,2,3$ & - \\
\hline & - Địa hình tương đối & $\mathrm{h}$ & 5,6 & 4 & - & $1,2,3$ \\
\hline
\end{tabular}

3.2.3 Đánh giá thích nghi đất đai trên cơ sở kết hợp (Matching) chất lương đất đai và yêu cầu sủ dụng đất của các loại hình sư dụng đất

Trong đề tài này, mức độ thích nghi đất đai của các loại hình sử dụng đất được xác định theo phương pháp hạn chế tối đa (the maximum limitation method), nghĩa là mức độ thích nghi của mỗi một loại hình sử dụng đẩt được xác định bởi yếu tố đất đai có mức độ hạn chế cao nhất.

Theo phương pháp này, đồng thời căn cứ vào bảng yêu cầu đất đai của các loại hình sử dụng đất được chọn (bảng 4) và đặc điểm của các đơn vị đất đai (bảng 3). Mức độ thích nghi đất đai kèm theo yếu tố hạn chế được xét cho từng LUT khi bố trí trên từng LMU cụ thể được trình bày trong bảng 5 . Mỗi đơn vị đất đai được đánh giá mức độ thích nghi cho 5 loại hình sử dụng đã được lựa chọn (Rau màu, Rừng ngập mặn, 
cây ăn quả, nuôi trồng thủy sản nước mặn và ruộng muối). Có 4 mức độ thích nghi được đề nghị: (1) S1: Thích nghi cao, (2) S2: Thích nghi trung bình, (3) S3: Ít thích nghi và (4) N: không thích nghi.

Ví dụ: Đơn vị đất đai số 1 , Thích nghi cao (S1) khi sản xuất rau màu, İt thích nghi (S3) với rừng ngập mặn, Thích nghi trung bình (S2) với cây ăn quả, Thích nghi cao (S1) cho nuôi trồng thủy sản, Thích nghi trung bình (S2) với sản xuất muối.

Bảng 5. Mức độ thích nghi của các loại hình sử dụng đất

\begin{tabular}{|l|c|c|c|c|c|r|}
\hline \multicolumn{1}{|c|}{ Số ĐVĐĐ } & Rau màu & Rù̀ng ngập mặn & Cây ăn quả & Thủy sản & Muối & \multicolumn{1}{c|}{ Tổng } \\
\hline 1. DVD1 & $\mathrm{S} 1$ & $\mathrm{~S} 3$ & $\mathrm{~S} 2$ & $\mathrm{~S} 1$ & $\mathrm{~S} 2$ & 618.06 \\
\hline 2. DVD2 & $\mathrm{S} 3$ & $\mathrm{~S} 2$ & $\mathrm{~N}$ & $\mathrm{~S} 1$ & $\mathrm{~S} 1$ & 605.23 \\
\hline 3. DVD3 & $\mathrm{S} 2$ & $\mathrm{~S} 2$ & $\mathrm{~S} 2$ & $\mathrm{~N}$ & $\mathrm{~N}$ & 77.22 \\
\hline 4. DVD4 & $\mathrm{S} 1$ & $\mathrm{~S} 2$ & $\mathrm{~S} 2$ & $\mathrm{~S} 3$ & $\mathrm{~N}$ & 4120.28 \\
\hline 5. DVD5 & $\mathrm{S} 1$ & $\mathrm{~S} 2$ & $\mathrm{~S} 2$ & $\mathrm{~S} 2$ & $\mathrm{~S} 2$ & 902.88 \\
\hline 6. DVD6 & $\mathrm{N}$ & $\mathrm{S} 1$ & $\mathrm{~N}$ & $\mathrm{~S} 1$ & $\mathrm{~S} 1$ & 22796.46 \\
\hline 7. DVD7 & $\mathrm{N}$ & $\mathrm{S} 1$ & $\mathrm{~N}$ & $\mathrm{~S} 1$ & $\mathrm{~S} 1$ & 12813.88 \\
\hline 8. DVD8 & $\mathrm{S} 3$ & $\mathrm{~S} 2$ & $\mathrm{~N}$ & $\mathrm{~S} 2$ & $\mathrm{~S} 2$ & 1017.17 \\
\hline 9. DVD9 & $\mathrm{S} 1$ & $\mathrm{~S} 2$ & $\mathrm{~N}$ & $\mathrm{~S} 1$ & $\mathrm{~S} 1$ & 2818.46 \\
\hline 10. DVD10 & $\mathrm{S} 2$ & $\mathrm{~S} 2$ & $\mathrm{~S} 3$ & $\mathrm{~S} 2$ & $\mathrm{~S} 2$ & 640.27 \\
\hline 11. DVD11 & $\mathrm{S} 2$ & $\mathrm{~S} 2$ & $\mathrm{~S} 1$ & $\mathrm{~N}$ & $\mathrm{~N}$ & 1411.27 \\
\hline 12. DVD12 & $\mathrm{S} 2$ & $\mathrm{~S} 3$ & $\mathrm{~S} 1$ & $\mathrm{~N}$ & $\mathrm{~N}$ & 969.12 \\
\hline 13. DVD13 & $\mathrm{S} 3$ & $\mathrm{~S} 3$ & $\mathrm{~S} 1$ & $\mathrm{~N}$ & $\mathrm{~N}$ & 744.55 \\
\hline 14. DVD14 & $\mathrm{S} 2$ & $\mathrm{~N}$ & $\mathrm{~S} 1$ & $\mathrm{~N}$ & $\mathrm{~N}$ & 884.81 \\
\hline Sông suối & & \multicolumn{7}{|l}{ Không đánh giá } & & & 20025.68 \\
\hline Tổng DTTN & & & & $\mathbf{7 0 4 4 5 . 3 4}$ \\
\hline
\end{tabular}

3.3 Đề xuất sử dụng đất

Căn cứ vào: (1) Phương hướng phát triển kinh tế- xã hội, quốc phòng, an ninh huyện Cần Giờ, (2) Kết quả điều tra xây dựng bản đồ đất và bản đồ thích nghi đất đai, (3) Kịch bản biến đổi khí hậu, nước biển dâng của TP. Hồ Chí Minh; định hướng sử dụng đất nông nghiệp của huyện Cần Giờ được chia ra 5 vùng như sau:

\section{- Vùng 1 (Vùng phát triển cây rau - Màu)}

Có quy mô diện tích là 723 ha, chiếm 1,03\% diện tích toàn huyện; tập trung các xã: Bình Khánh (310,3 ha) Lí Nhơn (224,2 ha), An Thới Đông (106,5 ha), Long Hòa (51,7 ha). Hướng sản xuất loại hình nông nghiệp công nghệ cao, áp dụng tiến bộ khoa học kĩ thuật để tăng hiệu quả kinh tế trên đơn vị diện tích. Theo qui hoạch, Cần Giờ sẽ là một khu đô thị nghỉ dưỡng sinh thái bậc nhất, vì vậy việc cung cấp rau xanh là vấn đề quan trọng.

\section{- Vùng 2 (Phát triển cây lâu năm như xoài, nhãn)}

Thường được trồng xen trong khu dân cư, qui mô khoảng 4.150 ha (5,89\%), phân bố cả 7 xã, thị trấn như sau: Bình Khánh 1.218,3 ha, An Thới Đông 1.187,2 ha, Long Hòa 534,3 ha, Lí Nhơn 417,8 ha, Tam Thôn Hiệp 386,5 ha, TT Cần Thạnh 357,8 ha và Thạnh An 47,7 ha. Cần chú ý đến địa hình khi bố trí cây lâu năm; nên chọn vùng đất có cao trình $>1 \mathrm{~m}$ (Bản đồ cao độ). Với cao trình $1-1,5 \mathrm{~m}$, cần đào mương, lên líp trước khi trồng (Hiện tại người dân không làm líp); với cao trình $>1,5 \mathrm{~m}$ có thể không cần lên líp. Sản xuất theo tiêu chuẩn GAP, nâng cao năng lực cạnh tranh, phục vụ tiêu dùng tại chỗ và xuất khẩu. 


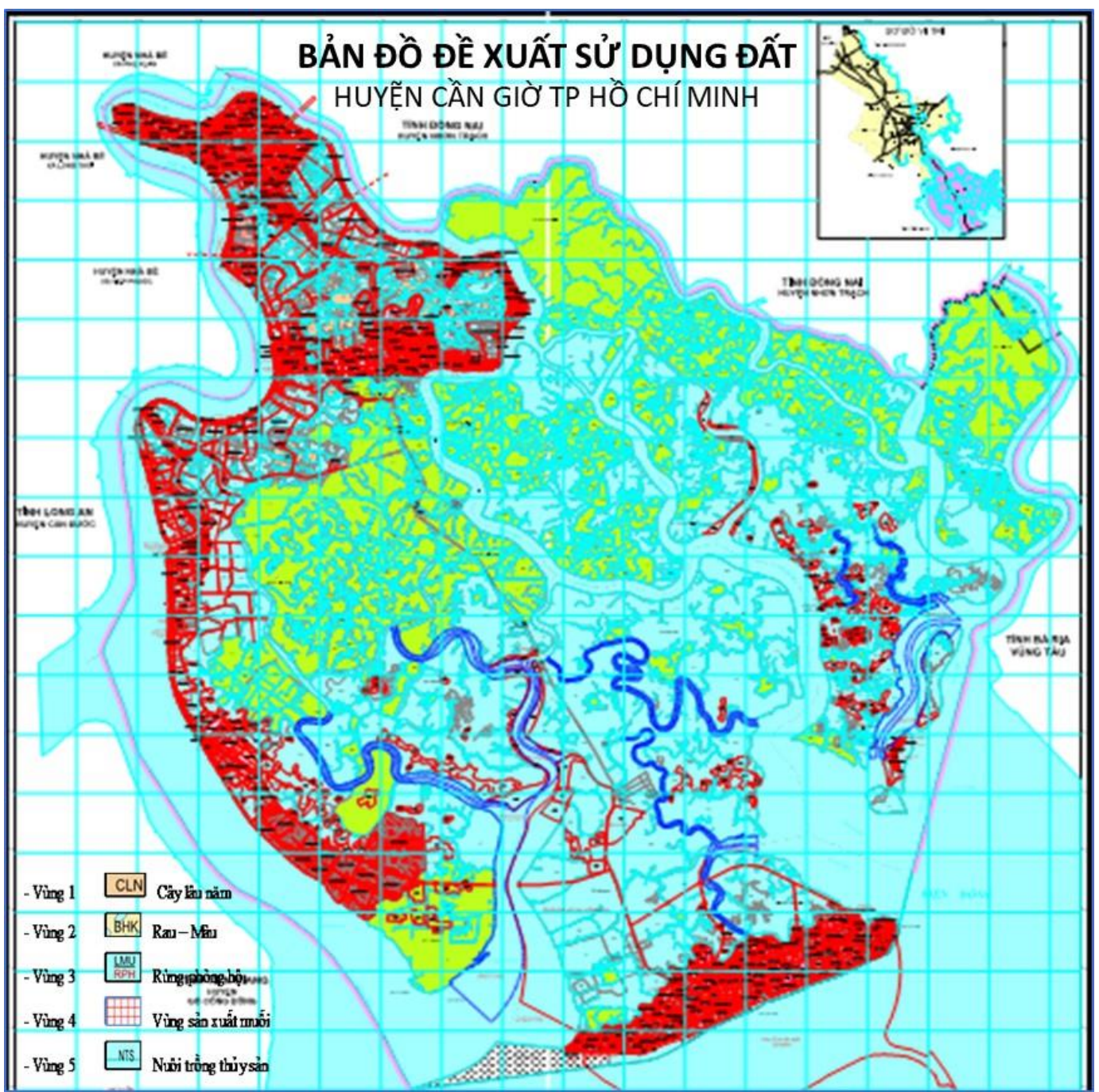

Hình 7. Bản đồ đề xuất sử dụng đất

\section{- Vùng 3 (Rừng phòng hộ)}

Quy mô 33.009 ha (46,86\%, gần một nửa DTTN) Cây rừng chủ yếu là nhóm cây rừng ngập mặn điển hình; chủ yếu là bần trắng, mấm trắng, các quần hợp đước đôi - bần trắng cùng xu ổi, trang, đưng v.v... và các loại nước lợ như bần chua, ô rô, dừa lá, ráng, v.v... Thảm cỏ biển với các loài ưu thế Halophyla sp., Halodule sp., và Thalassia $\mathrm{sp}$... Phân bố toàn huyện, trừ xã Bình Khánh. Theo kết quả Đề án kiểm kê, đánh giá và quản lý hệ thống tài nguyên du lịch trên địa bàn TP.HCM năm 2017 do Sở Du lịch cùng Trường ĐH Kinh tế Luật TP.HCM và Khoa Du lịch - Trường $\mathrm{H}$ Huế triển khai, với vị trí địa lý thuận lợi, Cần Giờ có lợi thế lớn về tài nguyên du lịch so với tài nguyên 24 quận, huyện của thành phố. Khu dự trữ sinh quyển Cần Giờ còn gọi là Rừng Sác, là một quần thể gồm các loài động, thực vật rừng trên cạn và thuỷ sinh, được hình thành trên vùng châu thổ rộng lớn của các cửa sông Đồng Nai, sông Sài Gòn và sông Vàm Cỏ. UNESCO đã công nhận đây là khu dự trữ sinh quyển thế giới vào ngày 21/1/2000 với hệ động thực vật đa dạng độc đáo điển hình của vùng ngập mặn. Nơi đây được công nhận là một khu du lịch trọng điểm quốc gia Việt Nam.

\section{- Vùng 4 (Nuôi trồng thủy sản)}

Quy mô 5.824 ha $(8,27 \%)$, phân bố khắp 7 xã, thị trấn, trong đó xã Lí Nhơn nhiều nhất 2.913 ha, ít nhất là TT Cần Thạnh 30 ha.

Tiếp tục duy trì nghề nuôi thủy sản theo hình thức quảng canh (đầm, đập) dưới tán rừng để khai thác giá trị từ nguồn tài nguyên thiên nhiên nhưng không làm ảnh hưởng đến hệ sinh thái rừng ngập mặn và pháp luật về bảo vệ, phát triển rừng của Nhà nước. Tiếp tục duy trì phát triển nghề nuôi nhuyễn thể, nuôi thủy sản lồng bè trên đất có mặt nước, đất bãi bồi ven sông, ven biển. Theo phương án quy hoạch vùng thủy sản 
được điều chỉnh, đầu tư hoàn chỉnh hạ tầng giao thông, thủy lợi, điện và các khu nội đồng vùng chuyên canh, đầu tư hoàn chỉnh hệ thống quan trắc cảnh báo môi trường.

- Vùng 5 (Sản xuất muối)

Qui mô khoảng 1.000 ha, chỉ tập trung 2 xã ven biển là Lí Nhơn 800 ha và Thạnh An 200 ha. Đây là vùng có những điều kiện điển hình, thuận lợi cho sản xuất muối (Nền đất sét, thủy triều ra vào thường xuyên...).

\section{KẾT LUÂN}

1. Đặc điểm đẩt: Đất huyện Cần Giờ được phân loại thành 3 Nhóm với 9 Đơn vị bản đồ; Ba nhóm đất được xác định: (1) Nhóm đất cát (2) Nhóm đất phèn và (3) Nhóm đất nhân tác.

2. Đánh giá thích nghi: Đánh giá thích nghi đất đai trên cơ sở kết hợp chất lượng đất đai và yêu cầu sử dụng đất của các loại hình sử dụng đất. Năm loại hình sử dụng đất được lựa chọn để đánh giá: (1) Rau màu, (2) Cây ăn quả (Xoài, nhãn), (3) Nuôi trồng thủy sản, (4) Rừng ngập mặn và (5) Sản xuất muối. Căn cứ vào yêu cầu sử dụng đất của 5 loại hình này, kết hợp tính chất đất đai (14 đơn vị đất đai) để đánh giá khả năng thích nghi; Mỗi loại hình sử dụng đất có thể thích nghi với nhiều đơn vị đất đai và ngược lại mỗi đơn vị đất đai cũng có thể thích nghi với nhiều loại hình sử dụng đất khác nhau.

3. Đề xuất khả năng sử dụng tài nguyên đất nông nghiệp huyện: Căn cứ kết quả đánh giá thích nghi đất đai, thực tiễn khảo sát hiệu quả kinh tế các loại hình sử dụng đất, kịch bản biến đổi khí hậu TP. Hồ Chí Minh, tham khảo định hướng phát triển kinh tế - xã hội của huyện Cần Giờ, chúng tôi đề xuất khả năng bố trí sử dụng đất nông nghiệp huyện Cần Giờ thành 5 vùng như sau: Vùng 1 (Vùng phát triển cây rau - Màu); Vùng 2 (Phát triển cây lâu năm như xoài, nhãn); Vùng 3 (Rừng phòng hộ); Vùng 4 (Nuôi trồng thủy sản) và Vùng 5 (Sản xuất muối).

\section{CẢM ƠN}

Nghiên cứu này được sự giúp đỡ của học viên cao học khóa 7, 8, ĐHCN TP. HCM; cán bộ Phân viện Qui hoạch và TKNN miền Nam. Tác giả xin chân thành cám ơn.

\section{TÀI LIỆU THAM KHẢO}

[1] Daniel C. Donato, J. Boone Kauffman, Daniel Murdiyarso, Sofyan Kurnianto, Melanie Stidham \& Markku Kanninen, "Mangroves among the most carbon-rich forests in the tropics," Nature Geoscience, vol. volume4, p. pages 293-297, 2011.

[2] Sở Tài nguyên và Môi trường TP. HCM, "Điều chỉnh Qui hoạch SDĐ đến năm 2020," Hồ Chí Minh, 2014.

[3] Viện Quy Hoạch và Thiết kế Nông nghiệp - Bộ Nông nghiệp và Phát triển Nông thôn , "TCVN 8409:2010, Qui trình đánh giá đất đai phục vụ qui hoạch sử dụng đất," Bộ Khoa học và Công nghệ, Hà Nội, 2010.

[4] FAO, "A framework for land evaluation," in Soils Bulletin 32, Rome, FAO, 1976.

[5] Trung tâm ứng dụng công nghệ địa chính. Điều chỉnh Quy hoạch sử dụng đất huyện Cần Giờ đến năm 2020 và kế hoạch sử dụng đất kì đầu (2014)., Sở Tài nguyên và Môi trường TP. HCM, Hồ Chí Minh, 2014.

[6] Phạm Quang Khánh, "Tài nguyên đất vùng Đông Nam Bộ - hiện trạng và tiềm năng," Nhà xuất bản Nông nghiệp, Hà Nội, 1995.

[7] Phan Liêu, Nguyễn Xuân Thành, Nguyễn Xuân Nhiệm , "Báo cáo thuyết minh Bản đồ đất thành phố Hồ Chí Minh," TP. Hồ Chí Minh, 1990.

[8] Phạm Quang Khánh, Nguyễn Xuân Nhiệm và ctg, "Báo cáo thuyết minh Bản đồ đất thành phố Hồ Chí Minh,", Hồ Chí Minh, 2004.

[9] Sở Khoa học và Công nghệ TP. Hồ Chí Minh, Nguyễn Đình Tứ, "Biên hội bản đồ địa chất công trình thành phố Hồ Chí Minh, tỷ lệ 1/50.000," TP. Hồ Chí Minh.

Ngày nhận bài: 28/04/2020

Ngày chấp nhận đăng: 04/09/2020 